\title{
ARTICLE
}

\section{Visualizing nanoscale 3D compositional fluctuation of lithium in advanced lithium-ion battery cathodes}

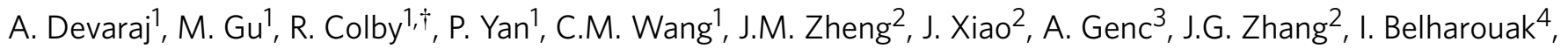 \\ D. Wang 5 , K. Amine ${ }^{5} \&$ S. Thevuthasan ${ }^{1,4}$
}

The distribution of cations in Li-ion battery cathodes as a function of cycling is a pivotal characteristic of battery performance. The transition metal cation distribution has been shown to affect cathode performance; however, $\mathrm{Li}$ is notoriously challenging to characterize with typical imaging techniques. Here laser-assisted atom probe tomography (APT) is used to map the three-dimensional distribution of $\mathrm{Li}$ at a sub-nanometre spatial resolution and correlate it with the distribution of the transition metal cations $(M)$ and the oxygen. As-fabricated layered $\mathrm{Li}_{1.2} \mathrm{Ni}_{0.2} \mathrm{Mn}_{0.6} \mathrm{O}_{2}$ is shown to have $\mathrm{Li}$-rich $\mathrm{Li}_{2} \mathrm{MO}_{3}$ phase regions and $\mathrm{Li}$-depleted $\mathrm{Li}\left(\mathrm{Ni}_{0.5} \mathrm{Mn}_{0.5}\right) \mathrm{O}_{2}$ regions. Cycled material has an overall loss of $\mathrm{Li}$ in addition to $\mathrm{Ni}-, \mathrm{Mn}$ - and Li-rich regions. Spinel $\mathrm{LiNi}_{0.5} \mathrm{Mn}_{1.5} \mathrm{O}_{4}$ is shown to have a uniform distribution of all cations. APT results were compared to energy dispersive spectroscopy mapping with a scanning transmission electron microscope to confirm the transition metal cation distribution.

\footnotetext{
${ }^{1}$ Environmental and Molecular Sciences Laboratory, Pacific Northwest National Laboratory, Richland, Washington 99354, USA. ${ }^{2}$ Energy and Environmental Directorate, Pacific Northwest National Laboratory, Richland, Washington 99354, USA. ${ }^{3}$ FEl Company, 5350 NE Dawson Creek Dr., Hillsboro, Oregon 97124, USA. ${ }^{4}$ Qatar Environment and Energy Research Institute, Qatar Foundation, PO box 5825, Doha, Qatar. ${ }^{5}$ Chemical Sciences and Engineering Division, Argonne National Laboratory, Argonne, Illinois 60439, USA. † Present address: ExxonMobil Research and Engineering Company, Annandale, New Jersey 08801, USA. Correspondence and requests for materials should be addressed to A.D. (email: arun.devaraj@pnnl.gov).
} 
T he portable consumer electronics revolution has driven the development of Li-ion batteries for efficient energy storage over the last decade ${ }^{1,2}$. Currently, there is also a strong interest in developing cost-effective, rapidly recharging Li-ion batteries suitable for long range electric vehicles ${ }^{3}$. As cathodes constitute a substantial portion of the volume and cost of a battery significant effort has been focused on the development of next-generation cathode materials ${ }^{4,5}$. Designing materials that can retain structural integrity after repeated cycling is a substantial challenge ${ }^{4}$. Fast ionic transport during electrochemical cycling of a material depends critically on the initial structure and crystal stability. The presence and stability of channels for fast Li-ion diffusion in cathode materials is an important design criterion for developing next-generation cathode materials for Li-ion batteries with higher capacity and long-term energy storage performance. Understanding nanoscale distribution of all of the elements that makeup Li-ion battery cathodes-especially Li ions-as a function of different synthesis procedures and extents of electrochemical cycling is a critical step towards developing new materials.

Li-rich layered cathode materials with the general formulae $\mathrm{Li}\left[\mathrm{Li}_{1 / 2-2 x / 3} \mathrm{Ni}_{x} \mathrm{Mn}_{2 / 3-x / 3}\right] \mathrm{O}_{2}$ where $0<x<1 / 3$ and more specifically, $\mathrm{Li}_{1.2} \mathrm{Ni}_{0.2} \mathrm{Mn}_{0.6} \mathrm{O}_{2}$-have been demonstrated with capacities $>250 \mathrm{mAhg}^{-1}$ : significantly higher than the $140-\mathrm{mAh} \mathrm{g}^{-1}$ capacity of the best $\mathrm{LiCoO}_{2}$ cathodes, used widely in consumer electronics ${ }^{6-9}$. Structurally layered $\mathrm{Li}_{1.2} \mathrm{Ni}_{0.2} \mathrm{Mn}_{0.6} \mathrm{O}_{2}$ is considered to be a phase mixture of the trigonal $\mathrm{Li} M \mathrm{O}_{2}(\mathrm{R}-3 \mathrm{~m})$ and monoclinic $\mathrm{Li}_{2} \mathrm{MO}_{3}(\mathrm{C} 2 / \mathrm{m})$ phases $(M=\mathrm{Ni}, \mathrm{Mn})$. Both of these structures can be represented as repeating layers of transition metal ions, $\mathrm{O}$ and Li. Recently, compositional segregation of $\mathrm{Ni}$ to surfaces and grain boundaries within some particles and partitioning of $\mathrm{Mn}$ away from Ni-rich regions in layered $\mathrm{Li}_{1.2} \mathrm{Ni}_{0.2} \mathrm{Mn}_{0.6} \mathrm{O}_{2}$ has been shown by energy dispersive spectroscopy (EDS) tomography ${ }^{10-12}$. By comparison of high-angle annular dark-field scanning transmission electron microscopy (HAADF-STEM) images to multislice simulations, the Ni-rich regions were shown to be consistent with an $\mathrm{R}-3 \mathrm{~m}$ phase and the Ni-deficient regions a $\mathrm{C} 2 / \mathrm{m}$ phase ${ }^{12}$. Electron energy-loss spectroscopy (EELS) analysis has indicated a $7: 9 \mathrm{Ni}: \mathrm{Mn}$ ratio (0.77) in the Ni-rich regions, best matching $\mathrm{Li}\left(\mathrm{Ni}_{0.5} \mathrm{Mn}_{0.5}\right) \mathrm{O}_{2}$, and a $5: 42 \mathrm{Ni:Mn}$ ratio (0.12) in the Ni-deficient regions, best matching $\mathrm{Li}_{2} \mathrm{MnO}_{3}$ (ref, 12). X-ray diffraction from as-prepared $\mathrm{Li}_{1.2} \mathrm{Ni}_{0.2} \mathrm{Mn}_{0.6} \mathrm{O}_{2}$ predominantly matched an R-3m structure, with the exception of three peaks between 20 and $25^{\circ}$ matching the $\mathrm{C} 2 / \mathrm{m}$ structure ${ }^{8,13,14}$. However, no detailed information was found on the distribution of $\mathrm{Li}$, or of its correlation to other elements in the lattice, within the published literature.

Under battery charge-discharge cycling, layered $\mathrm{Li}_{1.2} \mathrm{Ni}_{0.2}$ $\mathrm{Mn}_{0.6} \mathrm{O}_{2}$ cathodes were observed to develop a thin surface reconstruction layer, featuring structural transformation, $\mathrm{Mn}$ and $\mathrm{Ni}$ enrichment, oxygen vacancy formation and Li depletion ${ }^{15-17}$. Due to the structural and chemical change of the thin surface layer, it is believed to be a likely main contributor to voltage fading ${ }^{18}$. Furthermore, it has been proven that the surface layer continues to grow in thickness during continuous cycling ${ }^{15,19}$. EDS analysis of cycled layered $\mathrm{Li}_{1.2} \mathrm{Ni}_{0.2} \mathrm{Mn}_{0.6} \mathrm{O}_{2}$ has indicated composition variations even within the thin surface reconstruction layer ${ }^{15}$. To understand the structural degradation mechanism and seek a means to suppress the surface reconstruction, requires monitoring the evolution of all elements quantitatively at different states of cycling. However, despite substantial characterization efforts in previous studies, quantifying lithium depletion and subtle changes in oxygen concentration in the surface layer have been proven to be elusively challenging.
High-voltage spinel $\mathrm{LiNi}_{0.5} \mathrm{Mn}_{1.5} \mathrm{O}_{4}$, is considered one of the most promising candidates for hybrid electric vehicle batteries $2,20,21$. Stoichiometric $\mathrm{LiNi}_{0.5} \mathrm{Mn}_{1.5} \mathrm{O}_{4}$ is known to have a spinel structure with ordered $\mathrm{P}_{3} 32$ or disordered $\mathrm{Fd} 3 \mathrm{~m}$, depending on the post-synthesis annealing temperature ${ }^{22-24}$. This order-disorder phase transformation is expected to occur during higher temperature annealing as a result of generation or elimination of oxygen vacancies, by affecting the presence of $\mathrm{Mn}^{3+}$ in the lattice 23,24 . The disordered phase of $\mathrm{LiNi}_{0.5} \mathrm{Mn}_{1.5} \mathrm{O}_{4}$ is shown to have better electrochemical performance than the ordered spinel, owing to its higher electronic conductivity in the presence of increased disordered phase and/or $\mathrm{Mn}^{3+}$ concentration ${ }^{22,24-27}$.

The common obstacle to using these materials is capacity and voltage fading, believed to be closely related to a gradual structural evolution, governed by the spatial distribution of $\mathrm{Li}$ ions and their correlation with other ions in the lattice. Therefore, one of the great challenges facing the development of these high-voltage cathode materials for Li-ion batteries is to locate the spatial distribution of ions with sub-nanometre-scale spatial resolution. Aberration-corrected scanning and conventional transmission electron microscopy (S/TEM) ${ }^{28-31}$ and soft X-ray imaging/spectroscopy ${ }^{32}$ have been used to spatially map the transition metal cations within Li-ion battery cathodes, but these techniques do not have sufficient sensitivity to map Li at sub-nanometre scales, especially in three-dimensional (3D). Atom probe tomography (APT) is uniquely capable of providing quantitative $3 \mathrm{D}$, sub-nanometre-scale compositional characterization of oxides and composites ${ }^{33-38}$, with sensitivity for the $\mathrm{Li}$, the $\mathrm{O}$, and the transition metal cations ${ }^{39-50}$ in a Li-ion cathode material. While $\mathrm{Li}_{1.2} \mathrm{Ni}_{0.2} \mathrm{Mn}_{0.6} \mathrm{O}_{2}$ is expected to be a two-phase mixture, $\mathrm{LiNi}_{0.5} \mathrm{Mn}_{1.5} \mathrm{O}_{4}$ is expected to have a uniform cation distribution, providing a baseline evaluation of the ability of APT in unambiguously analysing the Li distribution in Li-ion battery cathode materials.

With this goal in mind, we provide here the first evidence for achieving unambiguous 3D sub-nanometre-scale spatially resolved mapping of $\mathrm{Li}, \mathrm{Ni}, \mathrm{Mn}$ and $\mathrm{O}$ in two categories of the advanced Li-ion battery cathode materials: layered- $\mathrm{Li}\left[\mathrm{Li}_{0.2}-\right.$ $\mathrm{Ni}_{0.2} \mathrm{Mn}_{0.6} \mathrm{O}_{2}$ and spinel $\mathrm{LiNi}_{0.5} \mathrm{Mn}_{1.5} \mathrm{O}_{4}$, using APT. APT results from as-fabricated and cycled layered- $\mathrm{Li}\left[\mathrm{Li}_{0.2} \mathrm{Ni}_{0.2} \mathrm{Mn}_{0.6}\right] \mathrm{O}_{2}$ are compared with obtain insights towards mechanisms for cycling dependent capacity loss.

\section{Results}

Element distribution in as-fabricated $\mathrm{Li}_{1.2} \mathrm{Ni}_{0.2} \mathrm{Mn}_{\mathbf{0 . 6}} \mathrm{O}_{2}$. Before APT analysis, the layered- $\mathrm{Li}\left[\mathrm{Li}_{0.2} \mathrm{Ni}_{0.2} \mathrm{Mn}_{0.6}\right] \mathrm{O}_{2}$ and spinel $\mathrm{LiNi}_{0.5} \mathrm{Mn}_{1.5} \mathrm{O}_{4}$ particles-henceforth, layered-LNMO and spinelLNMO-were analysed using STEM imaging and EDS mapping. An annular dark-field STEM image and EDS maps of a typical layered-LNMO particle are shown in Fig. 1a-e providing a clear evidence of non-uniform distribution of $\mathrm{Ni}$ and $\mathrm{Mn}$ within a nanoparticle. A layered-LNMO nanoparticle was subsequently analysed with APT using 20-pJ laser pulse energy to image and quantify $\mathrm{Li}, \mathrm{Ni}, \mathrm{Mn}$ and $\mathrm{O}$ distributions. In the atom-probe mass-to-charge spectra of layered-LNMO, elemental peaks of $\mathrm{Li}^{1+}, \mathrm{Ni}^{1+}, \mathrm{Ni}^{2+}, \mathrm{Mn}^{1+}, \mathrm{Mn}^{2+}$ and $\mathrm{O}^{1+}$ are visible, in addition to molecular species peaks for $\mathrm{O}_{2}^{1+}, \mathrm{MnO}^{1+}, \mathrm{MnO}^{2+}$, $\mathrm{MnO}_{2}^{1+}, \mathrm{MnO}_{2}^{2+}, \mathrm{MnO}_{3}^{1+}, \mathrm{MnO}_{3}^{2+}, \mathrm{MnO}_{4}^{1+}, \mathrm{Mn}_{2} \mathrm{O}^{2+}$, $\mathrm{Mn}_{2} \mathrm{O}_{2}^{1+}, \mathrm{Mn}_{2} \mathrm{O}_{3}^{1+}, \mathrm{Mn}_{2} \mathrm{O}_{4}^{1+}, \mathrm{Mn}_{2} \mathrm{O}_{5}^{1}+, \mathrm{Mn}_{2} \mathrm{O}_{6}^{1+}, \mathrm{NiO}^{1+}$, $\mathrm{NiO}^{2+}, \mathrm{NiO}_{2}^{1+}, \mathrm{NiO}^{2+}, \mathrm{Ni}_{2} \mathrm{O}^{2+}, \mathrm{NiO}_{3}^{1+}, \mathrm{MnNiO}^{2+}$, $\mathrm{MnNiO}_{2}^{1+}, \mathrm{MnNiO}_{3}^{1+}$ and $\mathrm{MnNiO}_{4}^{1+}$ (Supplementary Fig. 1). Of the total ion counts, $80.12 \%$ corresponded to elemental evaporation of $\mathrm{Li}, \mathrm{Ni}, \mathrm{Mn}$ and $\mathrm{O}$. Out of all the molecular species evaporated, $\mathrm{O}_{2}, \mathrm{MnO}, \mathrm{NiO}, \mathrm{MnO}_{2}$ and $\mathrm{MnO}_{3}$ combined 

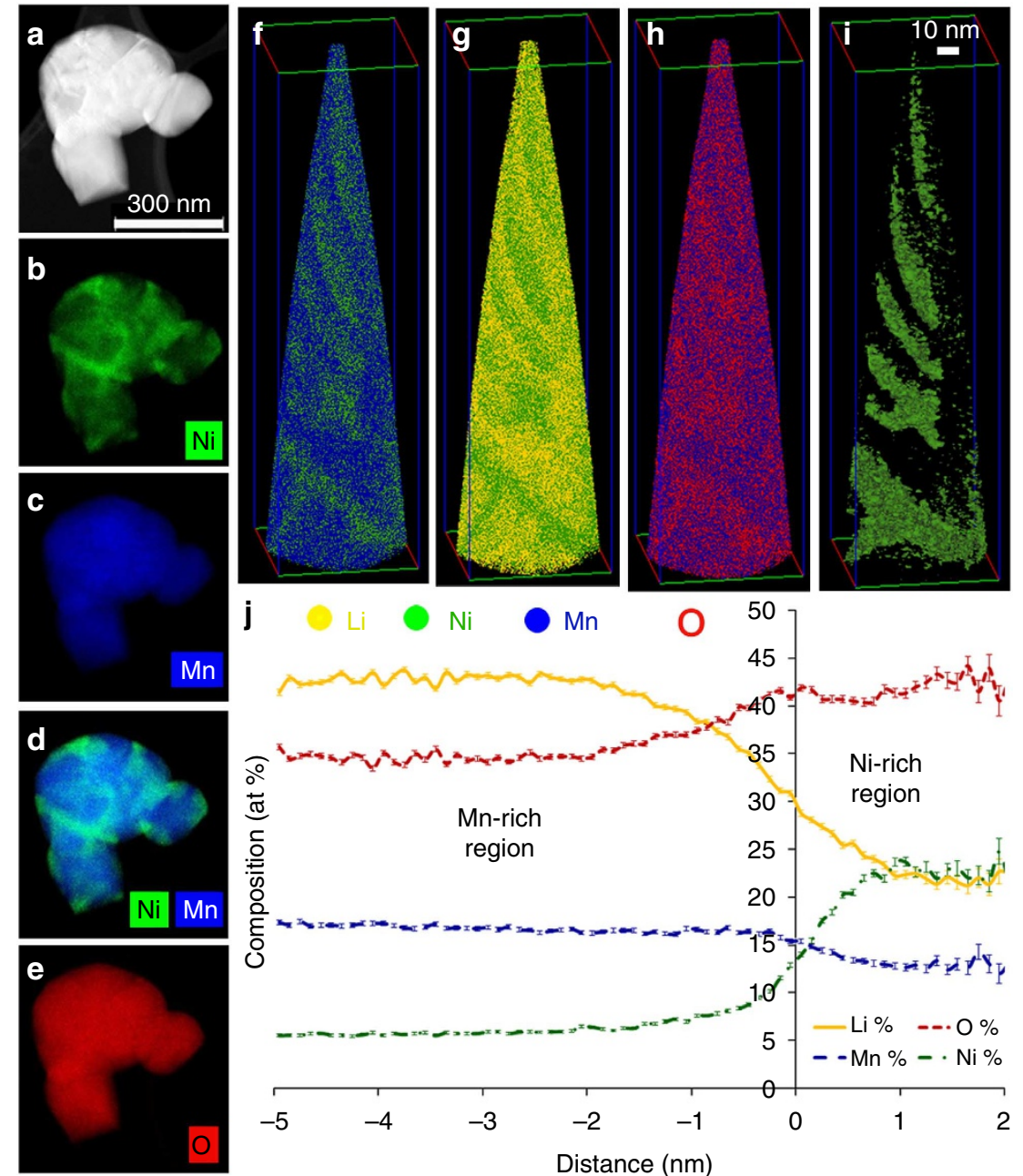

Figure 1 | Comparison of TEM EDS tomography with APT results of layered-LNMO. (a) STEM image and EDS maps of (b) Ni (green) (c) Mn (blue) (d) $\mathrm{Ni}$ and Mn composite map (e) O (red). Two element composite maps of the APT reconstructions are shown from $\mathbf{f}$ to $\mathbf{h}$ where each dot correspond to an atom in the reconstruction. (f) $\mathrm{Mn}$ (blue) and $\mathrm{Ni}$ (green) ion distribution (g) Li (yellow) and $\mathrm{Ni}$ (green) ion distribution and (h) O (red) and $\mathrm{Mn}$ (blue) ion distribution. (i) 13 at \% Ni isocomposition surface highlighting the Ni-rich regions in the reconstruction (j) Proximity histogram ${ }^{51}$ obtained across the 13 at\% $\mathrm{Ni}$ isocomposition surface showing concentration partitioning between Ni-rich and $\mathrm{Mn}$-rich regions.

constituted $18.37 \%$ of the total ion counts. All remaining complex ions corresponded to only $1.51 \%$ of the total ion counts. Such complex molecular species evaporation is commonly observed during laser-assisted APT analysis of other metal oxides, such as for $\mathrm{MgO}$ (ref. 33). The measured concentrations from the APT reconstruction were $41.61 \pm 0.03$ at $\% \mathrm{Li}, 6.13 \pm 0.01$ at $\% \mathrm{Ni}$, $16.60 \pm 0.02$ at $\% \mathrm{Mn}$, and $35.66 \pm 0.03$ at $\% \mathrm{O}$. The expected atomic concentrations are 30 at $\% \mathrm{Li}, 5$ at $\% \mathrm{Ni}, 15$ at $\% \mathrm{Mn}$, and 50 at $\% \mathrm{O}$.

Oxygen is known to be deficient during laser-assisted APT analysis of oxides except at extremely low laser energies ${ }^{33}$. To verify the accuracy of the APT quantification, the measured concentrations of $\mathrm{Li}, \mathrm{Mn}$ and $\mathrm{Ni}$ were renormalized independently of $\mathrm{O}$ and compared with the expected composition. In stoichiometric $\mathrm{Li}_{1.2} \mathrm{Ni}_{0.2} \mathrm{Mn}_{0.6} \mathrm{O}_{2}$, the $\mathrm{Li}$ fraction of the total cations, $\mathrm{Li} /(\mathrm{Li}+\mathrm{Mn}+\mathrm{Ni})$, should be $0.6 ; \mathrm{Mn}, 0.3$; and $\mathrm{Ni}, 0.1$. The measured cation fractions were $0.647,0.258$ and 0.095 , respectively. The concentration these specimens will be a function of the volume fraction of $\mathrm{Ni}$-rich and $\mathrm{Mn}$-rich regions sampled within the reconstruction, which may account for the minor variation from the expected stoichiometry. The APT reconstruction from layered-LNMO is shown in Fig. 1f-i). The non-uniform spatial distribution of Mn (blue) and $\mathrm{Ni}$ (green) ions shown in Fig. If is comparable to EDS maps shown in Fig. 1b-d. The ion map showing Li (yellow) with Ni (green) highlights the similarity of the spatial distribution of $\mathrm{Li}$ and $\mathrm{Mn}$. Both Li and Mn segregate away from regions of $\mathrm{Ni}$ enrichment (Fig. 1g). The $\mathrm{O}$ (red) and $\mathrm{Mn}$ (blue) ion map shows $\mathrm{O}$ segregating to regions with $\mathrm{Ni}$ enrichment (Fig. 1h). A 13 at $\% \mathrm{Ni}$ isocomposition surface image, shown in Fig. 1i, highlights regions enriched in $\mathrm{Ni}$ distributed throughout the reconstructed volume. The compositional partitioning across the $\mathrm{Ni}^{-}$and Mn-rich regions was quantified using a proximity histogram calculated perpendicular to the 13 at $\% \mathrm{Ni}$ isocomposition surface $^{51}$ (Fig. 1j). From the steady-state regions on either side of the interface in proximity histogram, the concentration of Ni-rich region was estimated to be $21.92 \pm 0.83$ at $\%$ Li, $12.89 \pm 0.67$ at $\% \mathrm{Mn}, 22.65 \pm 0.84$ at \% $\mathrm{Ni}$ and $42.53 \pm 0.99$ at $\% \mathrm{O}$ and the Mn-rich regions had a concentration of $42.94 \pm 0.29$ at $\% \mathrm{Li}, 16.91 \pm 0.22$ at $\% \mathrm{Mn}, 5.69 \pm 0.14$ at $\% \mathrm{Ni}$ and $34.36 \pm 0.28$ at \% O. The Ni:Mn ratios in the Ni-rich region and $\mathrm{Mn}$-rich region correspond to 1.76 and 0.34 , respectively. These Ni:Mn ratios are considerably higher than those previously obtained from $\mathrm{Mn}$ - or Ni-rich regions with STEM-EELS measurements, but two-dimensional (2D) STEM-based maps are measured in projection and thus an average of the 
composition through the thickness of the LMNO particle. The truly 3D measurements made by APT would therefore be expected to yield a higher maximum $\mathrm{Ni}: \mathrm{Mn}$ ratio in $3 \mathrm{D} \mathrm{Ni-}$ or Mn-rich regions.

To quantify the extent of phase separation, frequency distribution analysis was performed on the APT results. The entire APT data set was divided in-to 200-atom bins, the composition of each bin was calculated and a histogram was plotted. For a random solid solution, a binomial frequency distribution is expected. Any deviation from randomness will lead to a deviation from binomial distribution. The frequency distribution analysis of $\mathrm{Li}, \mathrm{Ni}, \mathrm{Mn}$ and $\mathrm{O}$ in layered-LNMO is shown in Fig. 2a-d. Pearson coefficient test can be used to measure the statistical relevance of the observed deviation from randomness ${ }^{52-54}$. Pearson coefficients tending towards 1 indicate statistically relevant extent of compositional segregation ${ }^{52,55}$. The Pearson coefficients for elemental $\mathrm{Li}$ and $\mathrm{Ni}$ obtained from the 200-atom bin size frequency distribution analysis were 0.869 and 0.792 , respectively; $\mathrm{Mn}$ and $\mathrm{O}$ had Pearson coefficient of 0.253 and 0.391 , respectively. The $\mathrm{NiO}, \mathrm{MnO}_{3}$ and $\mathrm{O}_{2}$ also had higher Pearson coefficient values of $0.535,0.201$ and 0.129 , respectively, with all other molecular species below 0.1 . Also all these elemental and molecular species with $>0.1$ Pearson coefficients resulted in $P$ values $<0.001$ at $95 \%$ confidence level during the null-hypothesis testing. These higher Pearson coefficient values and very low $P$ values reaffirm the existence of statistically significant extent of compositional segregation in asfabricated layered-LNMO.

$\mathrm{Li}, \mathrm{Ni}, \mathrm{Mn}$ and $\mathrm{O}$ distribution in Cycled layered-LNMO. On charge-discharge cycling of layered-LNMO cathodes with pre-existing Ni-rich regions, an additional Ni-rich surface reconstruction layer (SRL) has been found to form and grow as a function of cycling ${ }^{15-18}$. By detailed STEM, EDS and EELS measurements, a compositional partitioning of $\mathrm{Ni}$ and $\mathrm{Mn}$ has been observed within the SRL. As the Li concentration is expected to vary between the SRL and bulk of the cathode nanoparticle as a function of cycling, layered-LNMO cathodes cycled for 45 cycles were examined by APT. Needle-shaped APT specimens were fabricated from four different cycled layered-LNMO particles and during the needle preparation the needle specimen apex was kept very close to the top surface of the particles. The overall composition for each of the APT results from the four cycled layered-LNMO particles and two as-fabricated layered-LNMO particles are given below in Table 1.
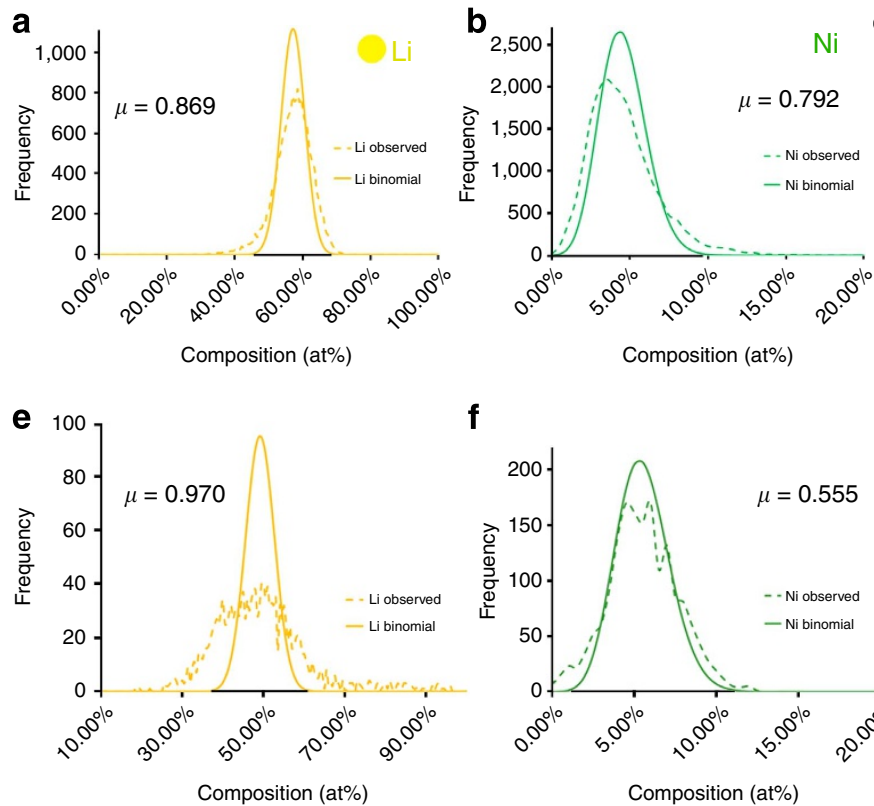

$\mathbf{f}$

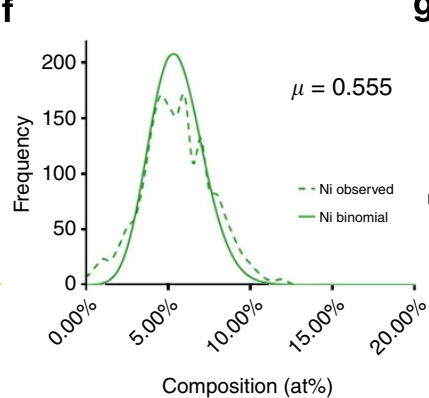

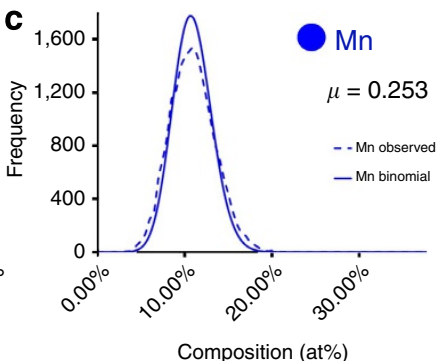

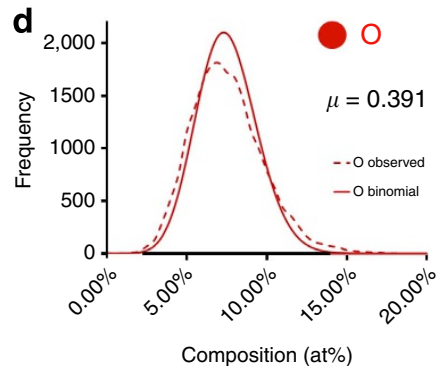

g

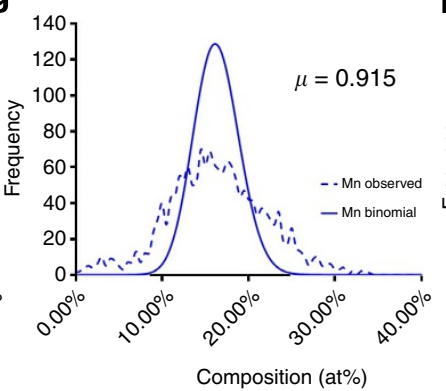

h

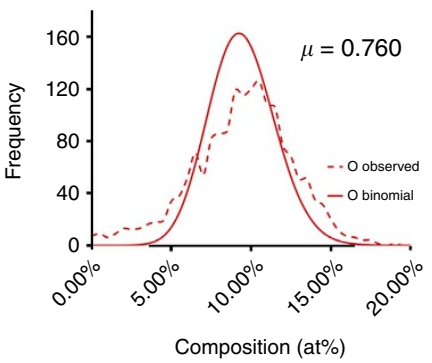

Figure 2 | Statistical analysis of element segregation in layered-LNMO. Frequency histogram of as-fabricated layered-LNMO (a) Li, (b) Ni, (c) Mn and (d) O with corresponding Pearson coefficients $(\mu)$ compared with frequency histogram of cycled layered-LNMO (e) Li, (f) $\mathrm{Ni}(\mathbf{g}) \mathrm{Mn},(\mathbf{h}) \mathrm{O}$ indicating a high degree of non-uniformity in distribution of $\mathrm{Li}, \mathrm{Ni}, \mathrm{Mn}$ and $\mathrm{O}$ in both as-fabricated and cycled $\mathrm{Li}_{1.2} \mathrm{Ni}_{0.2} \mathrm{Mn}_{0.6} \mathrm{O}_{2}$.

Table 1 | Composition of as-fabricated and cycled layered-LNMO.

\begin{tabular}{|c|c|c|c|c|c|}
\hline \multirow[t]{2}{*}{ Material } & \multirow[t]{2}{*}{ Particle } & \multicolumn{4}{|c|}{ Concentration (at \%) } \\
\hline & & $\mathbf{L i}$ & $\mathbf{0}$ & Mn & $\mathbf{N i}$ \\
\hline \multirow[t]{2}{*}{ As-fabricated layered-LNMO } & P1 & 41.61 & 35.66 & 16.6 & 6.13 \\
\hline & $\mathrm{P} 2$ & 40.75 & 36.25 & 17.03 & 5.96 \\
\hline \multirow[t]{4}{*}{ Cycled layered-LNMO after 45 cycles } & P1 & 30.67 & 35.37 & 24.4 & 9.56 \\
\hline & P2 & 32.59 & 33.86 & 25.61 & 7.94 \\
\hline & P3 & 34.59 & 34.6 & 23.21 & 7.6 \\
\hline & P4 & 34.91 & 34.48 & 21.38 & 9.23 \\
\hline
\end{tabular}



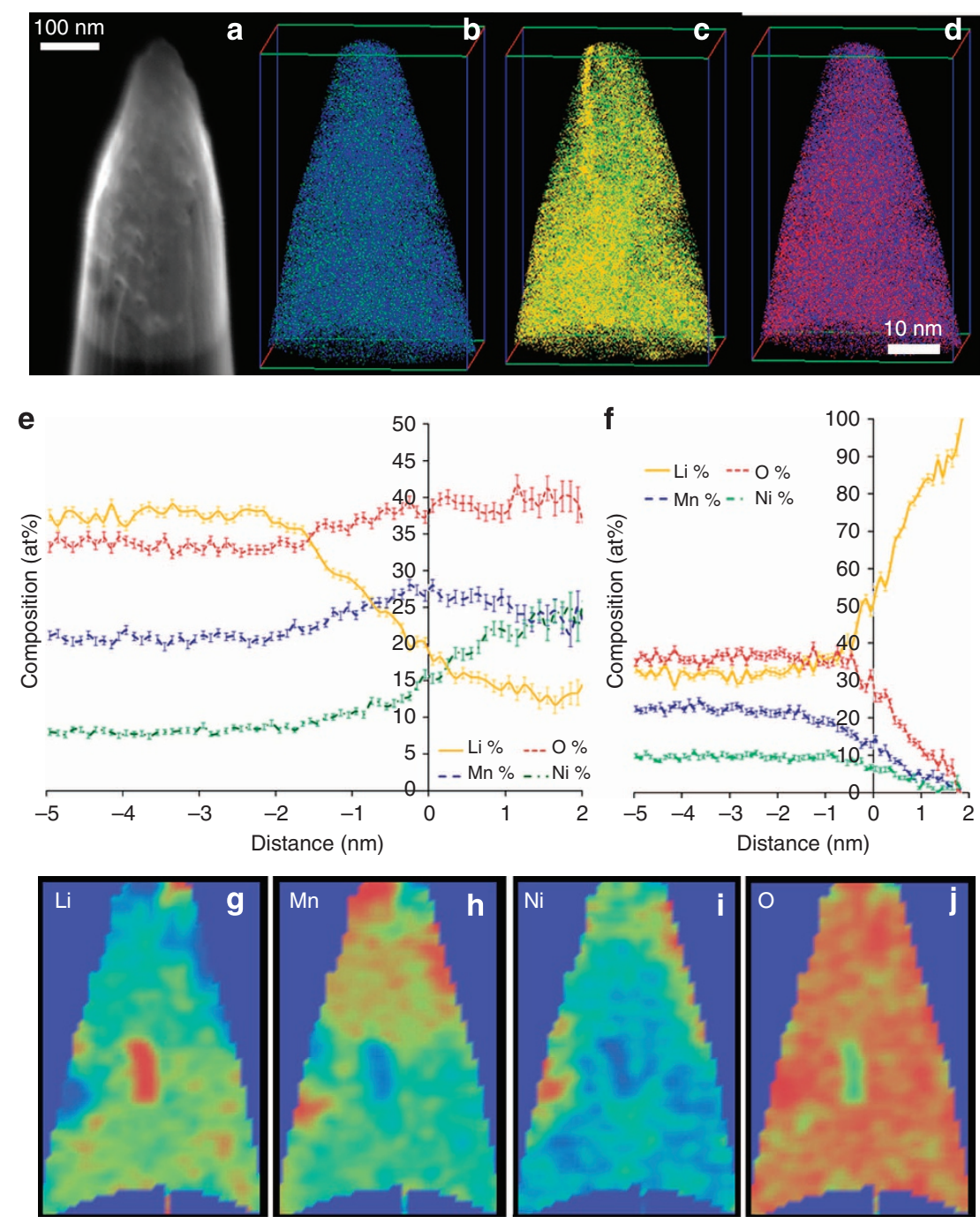

Figure 3 | APT results of cycled layered-LNMO. (a) The SEM image of the needle specimen of the cycled layered-LNMO (b-d) ion map of Mn and Ni, Ni and $\mathrm{Li}, \mathrm{Mn}$ and $\mathrm{O}$ respectively. (e) Proximity histogram across a 14 at \% $\mathrm{Ni}$ isocomposition surface and (f) proximity histogram across a Li-rich isocomposition surface. ( $\mathbf{g}-\mathbf{j}) 2 \mathrm{D}$ composition maps of of $\mathrm{Li}, \mathrm{Mn}, \mathrm{Ni}$ and $\mathrm{O}$ for a $5-\mathrm{nm}$ thick slice through a Li-rich inclusion.

A reduction in Li concentration and increase in the $\mathrm{Mn}$ and $\mathrm{Ni}$ concentration is observed in the cycled layered-LNMO specimens, in agreement with previous literature postulating a loss of $\mathrm{Li}$ as a function of cycling ${ }^{15,56}$. Two-dimensional composition plots of $\mathrm{Li}, \mathrm{Ni}, \mathrm{Mn}$ and $\mathrm{O}$, as shown in Fig. 3d-g, show that $\mathrm{Li}, \mathrm{Ni}$ and $\mathrm{Mn}$ partially segregate. A proximity histogram plotted across a Ni 14 at\% isocomposition surface, shown in Fig. 3e, illustrates the interface between the Ni-rich and $\mathrm{Ni}$-depleted regions within the reconstruction. The proxygram highlights that $\mathrm{Li}$ is depleted where $\mathrm{Ni}$ is enriched, and that $\mathrm{Mn}$ is enriched at the interface between $\mathrm{Ni}$ - and Li-rich regions. A second proximity histogram across a Li-rich region indicates a very high $\mathrm{Li}$ concentration reaching nearly 100 at $\%$. This apparently facetted region may correspond to a void formed inside the cathode nanoparticle during cycling, with an accumulation of Li. Comparison of the frequency histograms for $\mathrm{Li}, \mathrm{Mn}, \mathrm{Ni}$ and $\mathrm{O}$ in the cycled and asfabricated layered-LNMO indicates an increased phase separation of $\mathrm{Li}, \mathrm{Mn}$ and $\mathrm{O}$ (as indicated by the higher Pearson coefficient for $\mathrm{Li}, \mathrm{Mn}$ and $\mathrm{O}$ of $0.970,0.915,0.76$, respectively, shown in Fig. 2e-h). The Pearson coefficient of $\mathrm{Ni}$ was observed to be 0.555 , indicating $\mathrm{Ni}$ enrichment near the surface of cycled cathode materials. It is to be noted that recent STEM imaging and EDS measurements observed similar $\mathrm{Ni}$ enrichment in as- fabricated and cycled layered-LNMO particles. However, the pre-existing Ni-rich regions in the as-fabricated specimens were not captured within the APT reconstructions from the four cycled layered-LNMO particles. Pearson coefficient of molecular species of $\mathrm{NiO}(0.523), \mathrm{MnO}(0.281), \mathrm{MnO}_{2}(0.259), \mathrm{MnO}_{3}(0.353), \mathrm{Ni}_{2} \mathrm{O}$ (0.331), $\mathrm{O}_{2}(0.218)$ and $\mathrm{NiO}_{3}(0.165)$ were also above 0.1. Each elemental and molecular species with a $>0.1$ Pearson coefficient values also showed a $P$ value $<0.001$ at $95 \%$ confidence interval during null-hypothesis testing, establishing statistically significant segregation of these species in the cycled layered-LNMO.

Analysis of spinel-LNMO for technique validation. In contrast with layered-LNMO specimens, STEM-EDS mapping of spinel-LNMO indicates a uniform distribution of $\mathrm{Mn}, \mathrm{Ni}$ and $\mathrm{O}$, as shown in Fig. 4a-d. A mass-to-charge spectra from APT analysis of spinel-LNMO, provided in Supplementary Fig. 1, indicates a distribution of elemental and molecular ions similar to the as-fabricated layered-LNMO. Elemental ions of $\mathrm{Li}, \mathrm{Mn}, \mathrm{Ni}$ and $\mathrm{O}$ correspond to $74.23 \%$ of the ions detected; $24.2 \%$ of the ions detected correspond to $\mathrm{O}_{2}, \mathrm{MnO}, \mathrm{NiO}, \mathrm{MnO}_{2}$ and $\mathrm{MnO}_{3}$ combined, and the remaining $1.58 \%$ includes all other complex molecular ions. APT reconstructions of the spinel-LNMO 

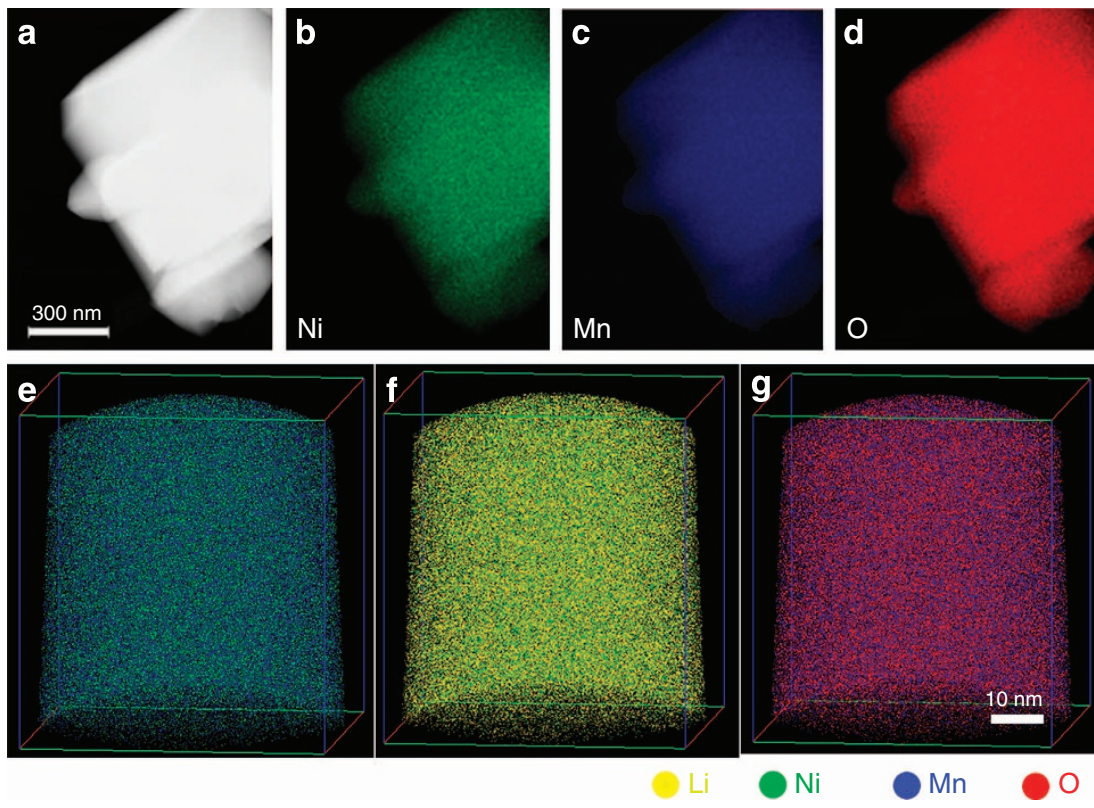

Figure 4 | Comparison of TEM EDS tomography with APT results of spinel-LNMO: TEM EDS mapping (a-d) and APT results (e-g) for LiNi ${ }_{0.5} \mathrm{Mn}_{1.5} \mathrm{O}_{4}$ showing uniform distribution of all elements.
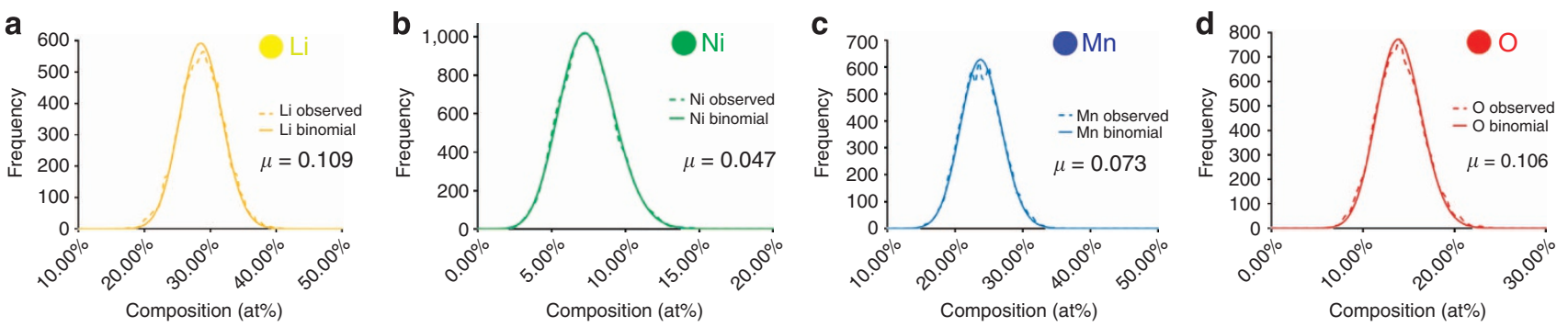

Figure 5 | Statistical analysis of element segregation in spinel-LNMO: Frequency distributions of $\mathrm{Li}, \mathrm{Ni}, \mathrm{Mn}$ and $\mathrm{O}$ in spinel-LNMO with corresponding Pearson coefficients $(\mu)$. (a-d) showing distributions rather close to uniform for $\mathrm{Li}, \mathrm{Ni}, \mathrm{Mn}$, and $\mathrm{O}$.

indicated uniform distributions of $\mathrm{Li}, \mathrm{Ni}, \mathrm{Mn}$ and $\mathrm{O}$, as shown in Fig. $4 \mathrm{e}-\mathrm{g}$, in agreement with the STEM-EDS results for $\mathrm{Ni}, \mathrm{Mn}$ and $\mathrm{O}$. The APT-measured composition of spinel-LNMO was $20.06 \pm 0.03$ at $\% \mathrm{Li}, 9.59 \pm 0.02$ at $\% \mathrm{Ni}, 27.28 \pm 0.03$ at $\% \mathrm{Mn}$ and $43.06 \pm 0.04$ at $\% \mathrm{O}$. The expected composition of these spinel-LNMO specimens is 14.29 at $\% \mathrm{Li}, 7.14$ at \% Ni, 21.43 at \% $\mathrm{Mn}$ and 57.14 at \% O. As it is expected that oxygen will be underestimated with the 20-pJ laser energy, it is more sensible to renormalize the $\mathrm{Li}, \mathrm{Ni}$ and $\mathrm{Mn}$ ratios excluding oxygen, for example, as $M /(\mathrm{Li}+\mathrm{Mn}+\mathrm{Ni})$. Cation ratios estimated in this manner were 0.35 for $\mathrm{Li}, 0.48$ for $\mathrm{Mn}$, and 0.17 for $\mathrm{Ni}$. The expected cation ratios for stoichiometric $\mathrm{LiNi}_{0.5} \mathrm{Mn}_{1.5} \mathrm{O}_{4}$ are 0.33 for $\mathrm{Li}, 0.5$ for $\mathrm{Mn}$, and 0.17 for $\mathrm{Ni}$, in excellent agreement with APT results, reinforcing the accuracy of APT in measuring $\mathrm{Li}, \mathrm{Ni}$ and $\mathrm{Mn}$ in these samples.

Frequency distribution analysis of the APT results from spinel LNMO was conducted to quantify the uniformity of the distribution of each element. Figure $5 \mathrm{a}-\mathrm{d}$ shows the observed frequency distributions of $\mathrm{Li}, \mathrm{Ni}, \mathrm{Mn}$ and $\mathrm{O}$ compared with a binomial distribution. It is clear that spinel-LNMO has a more uniform distribution compared to the as-fabricated layeredLNMO shown in Fig. 2. The Pearson coefficients estimated from the 200 atom bin size frequency distribution analysis for $\mathrm{Li}, \mathrm{Ni}$, $\mathrm{Mn}$ and $\mathrm{O}$ were $0.109,0.047,0.073$ and 0.106 respectively (shown as inset in Fig. 5), all indicating a very close to uniform distribution. The Pearson coefficient estimated for all the molecular species were also well below 0.1. A Pearson coefficient value close to 0 is indicative of a uniform distribution of elements ${ }^{52,55}$. The $P$ values estimated at a $95 \%$ confidence interval for $\mathrm{Li}$ and $\mathrm{O}$ was observed to be below 0.001 and the $P$ value for $\mathrm{Mn}$ and $\mathrm{Ni}$ were 0.095 and 0.568 . These $P$ values in combination with the Pearson coefficient values when compared with layered-LNMO results indicate that there is only a minor deviation from random distribution for $\mathrm{Li}$ and $\mathrm{O}$, but $\mathrm{Ni}$ and $\mathrm{Mn}$ are distributed rather uniformly in the spinel-LNMO APT result.

\section{Discussion}

The $\mathrm{Li}$ segregation to $\mathrm{Mn}$-rich, $\mathrm{Ni}$-depleted regions in asfabricated layered-LNMO suggests a $\mathrm{Li}_{2} \mathrm{MnO}_{3}$ phase with only minor $\mathrm{Ni}$. The Ni-enriched regions with lower $\mathrm{Li}$ concentration can be attributed to a $\mathrm{Li}\left(\mathrm{Ni}_{0.5} \mathrm{Mn}_{0.5}\right) \mathrm{O}_{2}$ phase. These APT results are consistent with STEM-EDS results from the same materials ${ }^{11}$. The APT results consistent with $\mathrm{Li}_{1.2} \mathrm{Ni}_{0.2} \mathrm{Mn}_{0.6} \mathrm{O}_{2}$ being a nanoscale composite mixture of $\mathrm{LiMO}_{2}(\mathrm{R}-3 \mathrm{~m})$ with $\mathrm{Li}_{2} \mathrm{MO}_{3}$ $(\mathrm{C} 2 / \mathrm{m})$ having varying amounts of $\mathrm{Li}, \mathrm{Mn}$, and $\mathrm{Ni}$ in each of these phases. Partitioning of $\mathrm{Li}, \mathrm{Ni}$, and $\mathrm{Mn}$ can lead to variation of local electrochemical properties. Recently, it was demonstrated that the capacity fading in layered-LNMO is closely related to the Ni distribution ${ }^{57}$, but those results lacked information about 
the Li distribution. It is plausible that the local depletion of $\mathrm{Li}$ leads to partial deactivation of a particle with cycling, which may contribute to the capacity and voltage fading. APT results from the cycled LNMO provide evidence for Li loss. Partial segregation of $\mathrm{Li}, \mathrm{Mn}$ and $\mathrm{Ni}$ to different regions in the cycled layered-LNMO is shown along with an increased extent of phase separation of $\mathrm{Li}, \mathrm{Mn}$ and $\mathrm{O}$.

Prior high spatial resolution studies of Li-ion cathode materials have similarly been left to infer the behaviour of Li by studying the changes in the local crystallography and the transition metal cation concentration. This study conclusively demonstrates that laserassisted APT can be used to not only quantify the $\mathrm{Ni}$ and $\mathrm{Mn}$ composition in $3 \mathrm{D}$ but also the $\mathrm{Li}$, and with sufficient accuracy to postulate the phase. There do not appear to be any barriers to studying the spatial distribution of $\mathrm{Li}$ for different synthesis methods, common cathode materials and for varying extents of electrochemical cycling of the cathode material. Quantifying the $\mathrm{Li}$ distribution by APT can impact the optimization of cathode synthesis procedures to achieve the highest performance, provide key insights toward the atomic-scale mechanism of capacity decay as a function of cycling, and aid in the effort to create novel Li-ion materials with prolonged lifetimes.

In summary, by comparing the as-fabricated and cycled layered-LNMO we have demonstrated a cycling-induced increased segregation of $\mathrm{Li}, \mathrm{Mn}$ and $\mathrm{O}$. The APT results of cycled layered-LNMO represent one of the first instances of direct evidence for Li loss in cycled cathode materials, consistent with previous TEM studies and typical explanations for irreversible capacity loss upon cycling of layered cathode materials. Comparison with compositionally uniform spinel-LNMO unambiguously establishes that the laser-assisted APT can differentiate $\mathrm{Li}$ segregation in battery-relevant materials at sub-nanometre-scale, in 3D. We anticipate significant application of APT analysis for understanding elemental distribution not just in the as-fabricated cathode materials, but also in electrochemically cycled materials to obtain important insight towards understanding capacity degradation in the cathode materials as a function of extent of cycling.

\footnotetext{
Methods

Material synthesis. $\mathrm{Li}_{1.2} \mathrm{Ni}_{0.2} \mathrm{Mn}_{0.6} \mathrm{O}_{2}$ was synthesized by wet chemical process as described briefly here. Nickel sulfate hexahydrate $\left(\mathrm{NiSO}_{4} \bullet 6 \mathrm{H}_{2} \mathrm{O}\right)$, manganese sulfate monohydrate $\left(\mathrm{MnSO}_{4} \bullet \mathrm{H}_{2} \mathrm{O}\right)$, sodium hydroxide $(\mathrm{NaOH})$, and ammonium hydroxide $\left(\mathrm{NH}_{3} \bullet \mathrm{H}_{2} \mathrm{O}\right)$ were used as the starting materials to prepare $\mathrm{Ni}_{0.25} \mathrm{M}$ $\mathrm{n}_{0.75}(\mathrm{OH})_{2}$ precursor. The precursor material was washed with hot water to remove residual sodium and sulfuric species, then filtered and dried inside a vacuum oven set at $80^{\circ} \mathrm{C}$ for $24 \mathrm{~h}$. $\mathrm{Ni}_{0.25} \mathrm{Mn}_{0.75}(\mathrm{OH})_{2}$ was mixed well with $\mathrm{Li}_{2} \mathrm{CO}_{3}$ and then calcined at $900 \mathrm{C}$ for $15 \mathrm{~h}$ to form the cathode materials. Detailed experimental setup for the synthesis of the materials was reported in Wang et al. ${ }^{58}$. A facile solidstate reaction method, which is easy to scale up for mass production, was adopted to synthesize the spinel $\mathrm{LiNi}_{0.5} \mathrm{Mn}_{1.5} \mathrm{O}_{4}$. In detail, $\mathrm{LiNi}_{0.5} \mathrm{Mn}_{1.5} \mathrm{O}_{4}$ was prepared by ball milling a mixture of $\mathrm{Li}_{2} \mathrm{CO}_{3}, \mathrm{NiO}$ and $\mathrm{MnCO}_{3}$ (all from Aldrich) in stoichiometric amount for $4 \mathrm{~h}$ followed by calcination at $900^{\circ} \mathrm{C}$ for $24 \mathrm{~h}$ in air with the heating rate of $10^{\circ} \mathrm{C} \mathrm{min}^{-1}$ and cooling rate of $5^{\circ} \mathrm{C} \mathrm{min}-1$.

Electrochemical cycling. The electrochemical cycling of layered-LNMO particles were conducted using coin cells configuration with metallic Li as counter electrode, separator of Celgard K1640 monolayer polyethylene membrane, with 1:2 volume ratio, $1 \mathrm{M}$ Lithium hexafluorophosphate (LiPF6) dissolved in ethyl carbonate and Dimethyl carbonate (DMC) electrolyte in an argon-filled MBraun glovebox. The 45 -cycle sample studied in this work was cycled at a rate of $0.1 \mathrm{C}$ between $2.0-4.7 \mathrm{~V}$ versus $\mathrm{Li} / \mathrm{Li}^{+}$at room temperature. The first cycle charge/discharge profile and 'charge and discharge' capacities as function of cycle numbers at $2.0-4.7 \mathrm{~V}$ versus $\mathrm{Li} / \mathrm{Li}+$ are given in Supplementary Fig. 2. The cycled coin cells were disassembled and the cycled electrode was immersed in DMC for $12 \mathrm{~h}$ followed by washing by DMC for three times. The washed electrodes were dried in vacuum for $12 \mathrm{~h}$. The cathode material was removed from the Al-foil and grounded to fine powders and deposited on a lacey carbon TEM grid for TEM imaging. The nanoparticles for APT specimens were lifted out from the TEM grid using lift-out method
} described below.
STEM/EDS mapping. The STEM and EDS mapping was performed using an FEI Tecnai Osiris microscope at $200 \mathrm{kV}$. The samples were dispersed onto a holeycarbon TEM grid and imaged accordingly. The FEI Tecnai Osiris microscope is equipped with a state-of-the-art Super-X EDS detector system, which allows efficient and fast mapping at nanoscale.

Atom probe specimen preparation. Needle-shaped specimens for APT analysis were prepared by lift-out procedure using an FEI Helios 600 Nanolab focused-ionbeam/scanning electron microscope (FIB/SEM). $\mathrm{Li}_{1.2} \mathrm{Ni}_{0.2} \mathrm{Mn}_{0.6} \mathrm{O}_{2}$ nanoparticles were dispersed on a Si substrate; individual nanoparticles were lifted out by contact with OmniProbe nanomanipulator and transferred onto a Si microtip array. Once the nanoparticles were placed on top of Si microtips, electron-beam-assisted $\mathrm{Pt}$ deposition was used to coat the individual nanoparticles. All manipulation of nanoparticles and Pt deposition were done using only the electron beam without Ga-ion beam imaging. After Pt deposition, the nanoparticles were subjected to annular milling using Ga-ion beam to form the final needle specimens of the nanoparticles attached to the Si microtip array. If cavities were observed between a nanoparticle and the Si microtip, electron-beam-assisted Pt deposition was also performed during annular milling. Initial annular milling was conducted at $30 \mathrm{kV}$ and final milling was performed using $2 \mathrm{kV}$ to minimize Ga contamination in the final needle specimen. A schematic of the specimen preparation method is given in Supplementary Fig. 3

Atom probe tomography. Laser-assisted APT analysis was conducted using a CAMECA LEAP $4000 \times$ HR atom probe tomography system with a $355-\mathrm{nm}$ ultraviolet laser, 20-pJ laser pulse energy, $40 \mathrm{~K}$ specimen temperature and evaporation rate maintained at 0.005 atoms per pulse. APT data were reconstructed and analysed using IVAS 3.6.6 software.

\section{References}

1. Tarascon, J. M. \& Armand, M. Issues and challenges facing rechargeable lithium batteries. Nature 414, 359-367 (2001).

2. Croy, J. R., Abouimrane, A. \& Zhang, Z. Next-generation lithium-ion batteries The promise of near-term advancements. MRS Bull. 39, 407-415 (2014).

3. Etacheri, V., Marom, R., Elazari, R., Salitra, G. \& Aurbach, D. Challenges in the development of advanced Li-ion batteries: a review. Energy Environ. Sci. 4, 3243-3262 (2011).

4. Goodenough, J. B. \& Kim, Y. Challenges for rechargeable Li batteries. Chem. Mater. 22, 587-603 (2010).

5. Ellis, B. L., Lee, K. T. \& Nazar, L. F. Positive electrode materials for Li-ion and Li-batteries. Chem. Mater. 22, 691-714 (2010).

6. Thackeray, M. M., Johnson, C. S., Vaughey, J. T., Li, N. \& Hackney, S. A. Advances in manganese-oxide 'composite' electrodes for lithium-ion batteries. J. Mater. Chem. 15, 2257-2267 (2005).

7. Armstrong, A. R. et al. Demonstrating oxygen loss and associated structural reorganization in the lithium battery cathode $\mathrm{Li}[\mathrm{Ni} 0.2 \mathrm{Li} 0.2 \mathrm{Mn} 0.6] \mathrm{O}-2$. J. Am. Chem. Soc. 128, 8694-8698 (2006).

8. Kim, J. S., Johnson, C. S., Vaughey, J. T., Thackeray, M. M. \& Hackney, S. A. Electrochemical and structural properties of $x \operatorname{Li}(2) \mathrm{M}^{\prime} \mathrm{O}-3$ center $\operatorname{dot}(1-\mathrm{x})$ LiMn0.5Ni0.5O2 electrodes for lithium batteries $\left(\mathrm{M}^{\prime}=\mathrm{Ti}, \mathrm{Mn}, \mathrm{Zr} ; 0<=\mathrm{x}\right.$ $<=0.3$ ). Chem. Mater. 16, 1996-2006 (2004).

9. Thackeray, M. M., Kang, S. H., Johnson, C. S., Vaughey, J. T., Benedek, R. \& Hackney, S. A. Li2MnO3-stabilized LiMO2 $(\mathrm{M}=\mathrm{Mn}, \mathrm{Ni}, \mathrm{Co})$ electrodes for lithium-ion batteries. J. Mater. Chem. 17, 3112-3125 (2007).

10. Genc, A. et al. XEDS STEM tomography for 3D chemical characterization of nanoscale particles. Ultramicroscopy 131, 24-32 (2013).

11. Gu, M. et al. Conflicting roles of nickel in controlling cathode performance in lithium ion batteries. Nano Lett. 12, 5186-5191 (2012).

12. Gu, M. et al. Nanoscale phase separation, cation ordering, and surface chemistry in pristine Li1.2Ni0.2Mn0.6O2 for Li-ion batteries. Chem. Mater. 25, 2319-2326 (2013).

13. Hong, J., Seo, D. H., Kim, S. W., Gwon, H., Oh, S. T. \& Kang, K. Structural evolution of layered $\mathrm{Li} 1.2 \mathrm{Ni} 0.2 \mathrm{Mn} 0.6 \mathrm{O} 2$ upon electrochemical cycling in a $\mathrm{Li}$ rechargeable battery. J. Mater. Chem. 20, 10179-10186 (2010).

14. Lei, C. H., Bareno, J., Wen, J. G., Petrov, I., Kang, S. H. \& Abraham, D. P. Local structure and composition studies of $\mathrm{Li1} .2 \mathrm{Ni} 0.2 \mathrm{Mn} 0.6 \mathrm{O} 2$ by analytical electron microscopy. J. Power Sources 178, 422-433 (2008).

15. Yan, P. et al. Evolution of lattice structure and chemical composition of the surface reconstruction layer in $\mathrm{Li1} .2 \mathrm{Ni0} .2 \mathrm{Mn} 0.6 \mathrm{O} 2$ cathode material for lithium ion batteries. Nano Lett. 15, 514-522 (2015).

16. Lin, F. et al. Surface reconstruction and chemical evolution of stoichiometric layered cathode materials for lithium-ion batteries. Nat. Commun. 5, 3529 (2014).

17. Boulineau, A., Simonin, L., Colin, J. F., Bourbon, C. \& Patoux, S. First evidence of manganese-nickel segregation and densification upon cycling in Li-Rich layered oxides for lithium batteries. Nano Lett. 13, 3857-3863 (2013).

18. Xu, B., Fell, C. R., Chi, M. F. \& Meng, Y. S. Identifying surface structural changes in layered Li-excess nickel manganese oxides in high voltage lithium 
ion batteries: A joint experimental and theoretical study. Energy Environ. Sci. 4, 2223-2233 (2011).

19. Gu, M. et al. Formation of the spinel phase in the layered composite cathode used in Li-ion batteries. ACS Nano 7, 760-767 (2013).

20. Xiao, J. et al. High-performance LiNi0.5Mn1.5O4 Spinel controlled by Mn3 + concentration and ste disorder. Adv. Mater. 24, 2109-2116 (2012).

21. Hassoun, J., Panero, S., Reale, P. \& Scrosati, B. A new, safe, high-rate and highenergy polymer lithium-ion battery. Adv. Mater. 21, 4807-4810 (2009).

22. Kunduraci, M., Al-Sharab, J. F. \& Amatucci, G. G. High-power nanostructured LiMn2-xNixO4 high-voltage lithium-ion battery electrode materials: Electrochemical impact of electronic conductivity and morphology. Chem. Mater. 18, 3585-3592 (2006).

23. Lee, E. \& Persson, K. A. Revealing the coupled cation interactions behind the electrochemical profile of LixNi0.5Mn1.5O4. Energy Environ. Sci. 5, 6047-6051 (2012).

24. Kim, J. H., Myung, S. T., Yoon, C. S., Kang, S. G. \& Sun, Y. K. Comparative

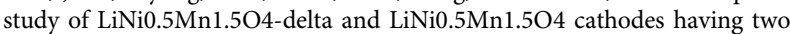
crystallographic structures: Fd(3)over-barm and P4(3)32. Chem. Mater. 16, 906-914 (2004).

25. Wang, L. P., Li, H., Huang, X. J. \& Baudrin, E. A comparative study of Fd-3m and P4(3)32 'LiNi0.5Mn1.5O4'. Solid State Ionics 193, 32-38 (2011).

26. Patoux, S. et al. High voltage nickel manganese spinel oxides for Li-ion batteries. Electrochim. Acta 53, 4137-4145 (2008).

27. Zheng, J. M. et al. Enhanced Li + ion transport in LiNi0.5Mn1.5O4 through control of site disorder. Phys. Chem. Chem. Phys. 14, 13515-13521 (2012).

28. Wang, F. et al. Tracking lithium transport and electrochemical reactions in nanoparticles. Nat. Commun. 3, 1-8 (2012).

29. Shao-Horn, Y., Croguennec, L., Delmas, C., Nelson, E. C. \& O'Keefe, M. A. Atomic resolution of lithium ions in LiCoO2. Nat. Mater. 2, 464-467 (2003).

30. Chung, S. Y., Choi, S. Y., Yamamoto, T. \& Ikuhara, Y. Atomic-scale visualization of antisite defects in $\mathrm{LiFePO}(4)$. Phys. Rev. Lett. 100, 125502 (2008).

31. Oshima, Y. et al. Direct imaging of lithium atoms in LiV2O4 by spherical aberration-corrected electron microscopy. J. Electron. Microsc. 59, 457-461 (2010).

32. Liu, X. S. et al. Distinct charge dynamics in battery electrodes revealed by in situ and operando soft X-ray spectroscopy. Nat. Commun. 4, 1-8 (2013).

33. Devaraj, A., Colby, R., Hess, W. P., Perea, D. E. \& Thevuthasan, S. Role of photoexcitation and field ionization in the measurement of accurate oxide stoichiometry by laser-assisted atom probe tomography. J. Phys. Chem. Lett. 4, 993-998 (2013)

34. Kelly, T. F. \& Larson, D. J. The second revolution in atom probe tomography. MRS Bull. 37, 150-158 (2012).

35. Kelly, T. F. \& Miller, M. K. Invited review article: atom probe tomography. Rev. Sci. Instrum. 78 (2007).

36. Kelly, T. F. et al. Atom probe tomography of electronic materials. Annu. Rev. Mater. Res. 37, 681-727 (2007).

37. Vilayurganapathy, S. et al. Subsurface synthesis and characterization of $\mathrm{Ag}$ nanoparticles embedded in MgO. Nanotechnology 24, 1-8 (2013).

38. Devaraj, A., Colby, R., Vurpillot, F. \& Thevuthasan, S. Understanding atom probe tomography of oxide-supported metal nanoparticles by correlation with atomic-resolution electron microscopy and field evaporation simulation. J. Phys. Chem. Lett. 5, 1361-1367 (2014).

39. Greiwe, G. H., Balogh, Z. \& Schmitz, G. Atom probe tomography of lithiumdoped network glasses. Ultramicroscopy 141, 51-55 (2014).

40. Heard, D. W., Boselli, J., Rioja, R., Marquis, E. A., Gauvin, R. \& Brochu, M. Interfacial morphology development and solute trapping behavior during rapid solidification of an Al-Li-Cu alloy. Acta Mater. 61, 1571-1580 (2013).

41. Krug, M. E., Seidman, D. N. \& Dunand, D. C. Creep properties and precipitate evolution in Al-Li alloys microalloyed with Sc and Yb. Mat. Sci. Eng. A-Struct. 550, 300-311 (2012).

42. Gault, B. et al. Atom probe microscopy investigation of $\mathrm{Mg}$ site occupancy within delta' precipitates in an Al-Mg-Li alloy. Scripta Mater. 66, 903-906 (2012).

43. Deschamps, A., Sigli, C., Mourey, T., de Geuser, F., Lefebvre, W. \& Davo, B. Experimental and modelling assessment of precipitation kinetics in an $\mathrm{Al}-\mathrm{Li}$ Mg alloy. Acta Mater. 60, 1917-1928 (2012).

44. Gault, B., de Geuser, F., Bourgeois, L., Gabble, B. M., Ringer, S. P. \& Muddle, B. C. Atom probe tomography and transmission electron microscopy characterisation of precipitation in an Al-Cu-Li-Mg-Ag alloy. Ultramicroscopy 111, 683-689 (2011).

45. Monachon, C., Krug, M. E., Seidman, D. N. \& Dunand, D. C. Chemistry and structure of core/double-shell nanoscale precipitates in Al-6.5Li-0.07Sc-0.02 Yb (at.\%). Acta Mater. 59, 3398-3409 (2011).

46. Krug, M. E., Dunand, D. C. \& Seidman, D. N. Effects of Li additions on precipitation-strengthened $\mathrm{Al}-\mathrm{Sc}$ and $\mathrm{Al}-\mathrm{Sc}-\mathrm{Yb}$ alloys. Acta Mater. 59, 1700-1715 (2011)
47. Xiong, X. Y., Moutsos, S., King, R. \& Muddle, B. Quantitative analysis of precipitate compositions in an $\mathrm{Al}-\mathrm{Li}-\mathrm{Mg}-\mathrm{Cu}$ alloy using atom probe tomography. Mater. Sci. Forum 654-656, 914-917 (2010).

48. Krug, M. E., Dunand, D. C. \& Seidman, D. N. Composition profiles within $\mathrm{Al}(3) \mathrm{Li}$ and $\mathrm{Al}(3) \mathrm{Sc} / \mathrm{Al}(3) \mathrm{Li}$ nanoscale precipitates in aluminum. Appl. Phys. Lett. 92, 124107 (2008).

49. Santhanagopalan, D. et al. Effects of laser energy and wavelength on the analysis of $\mathrm{LiFePO} 4$ using laser assisted atom probe tomography. Ultramicroscopy 148, 57-66 (2015).

50. Diercks, D. R. et al. Evidence for anisotropic mechanical behavior and nanoscale chemical heterogeneity in cycled $\mathrm{LiCoO}_{2}$. J. Electrochem. Soc. 161, F3039-F3045 (2014).

51. Hellman, O. C., Vandenbroucke, J. A., Rusing, J., Isheim, D. \& Seidman, D. N Analysis of three-dimensional atom-probe data by the proximity histogram. Microsc. Microanal. 6, 437-444 (2000).

52. Gault, B., Moody, M. P., Cairney, J. M. \& Ringer, S. P. Atom Probe Microscopy (Springer, 2012).

53. Moody, M. P., Stephenson, L. T., Ceguerra, A. V. \& Ringer, S. P. Quantitative binomial distribution analyses of nanoscale like-solute atom clustering and segregation in atom probe tomography data. Microsc. Res. Techniq. 71, 542-550 (2008).

54. Moody, M. P., Stephenson, L. T., Liddicoat, P. V. \& Ringer, S. P. Contingency table techniques for three dimensional atom probe tomography. Microsc. Res. Techniq. 70, 258-268 (2007).

55. Devaraj, A. et al. Nanoscale phase separation in epitaxial Cr-Mo and $\mathrm{Cr}-\mathrm{V}$ alloy thin films studied using atom probe tomography: Comparison of experiments and simulation. J. Appl. Phys. 116, 193512 (2014).

56. Yan, P. et al. Probing the degradation mechanism of Li2MnO3 cathode for Li-ion batteries. Chem. Mater. 27, 975-982 (2015).

57. Zheng, J. et al. Mitigating voltage fade in cathode materials by improving the atomic level uniformity of elemental distribution. Nano Lett. 14, 2628-2635 (2014).

58. Wang, D. P., Belharouak, I., Koenig, G. M., Zhou, G. W. \& Amine, K. Growth mechanism of $\mathrm{Ni} 0.3 \mathrm{Mn} 0.7 \mathrm{CO} 3$ precursor for high capacity Li-ion battery cathodes. J. Mater. Chem. 21, 9290-9295 (2011).

\section{Acknowledgements}

The funding for the research described in this paper was from a Laboratory Directed Research and Development fund from the Chemical Imaging Initiative at Pacific Northwest National Laboratory (PNNL). PNNL is a multiprogram national laboratory operated by Battelle Memorial Institute, under Contract No. DE-AC05-76RLO1830 for the U.S. Department of Energy (DOE). RC would like to thank the Wiley Postdoctoral Fellowship for research funding. All the characterization was conducted in the William R. Wiley Environmental Molecular Sciences Laboratory (EMSL), a national scientific user facility sponsored by DOE's Office of Biological and Environmental Research and located at PNNL.

\section{Author contributions}

A.D., R.C. and S.T. conceived the research and A.D. executed the APT specimen preparation, APT experiments and analysed the results. M.G., P.Y., C.M.W. and A.G. conducted the STEM-EDS mapping. J.M.Z., J.X., J.G.Z., I.B., D.W. and K.A. synthesized the cathode materials and conducted the electrochemical cycling. A.D. and R.C. wrote the manuscript with input from all the other authors.

\section{Additional information}

Supplementary Information accompanies this paper at http://www.nature.com/ naturecommunications

Competing financial interests: The authors declare no competing financial interests

Reprints and permission information is available online at http://npg.nature.com/ reprintsandpermissions/

How to cite this article: Devaraj, A. et al. Visualizing nanoscale 3D compositional fluctuation of lithium in advanced lithium-ion battery cathodes. Nat. Commun. 6:8014 doi: 10.1038/ncomms9014 (2015).

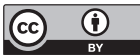

This work is licensed under a Creative Commons Attribution 4.0 International License. The images or other third party material in this article are included in the article's Creative Commons license, unless indicated otherwise in the credit line; if the material is not included under the Creative Commons license, users will need to obtain permission from the license holder to reproduce the material. To view a copy of this license, visit http://creativecommons.org/licenses/by/4.0/ 